\title{
ANALISA PENGARUH VARIASI FRAKSI VOLUME TERHADAP DENSITAS DAN KEKUATAN TARIK SERAT PELEPAH PISANG - EPOKSI
}

\author{
Nanang Endriatno \\ Staf Pengajar Program Studi Teknik Mesin Fakultas Teknik Universitas Halu Oleo, Kendari \\ E-mail: nanangendriatno@yahoo.com
}

\begin{abstract}
Abstrak
Penelitian ini bertujuan untuk menganalisis pengaruh fraksi volume terhadap kekuatan tarik dan densitas bahan komposit serat pelepah pisang-epoksi. Salah satu faktor yang sangat penting dalam menentukan karakteristik material komposit adalah fraksi volume antara matriks dan serat. Pada penelitian ini menggunakan serat pelepah pisang kepok (Musa Paradisiaca) karena memiliki bahan baku yang melimpah dan ramah lingkungan. Pengujian kekautan tarik dilakukan dengan spesimen yang disesuaikan dengan standar ASTM 638-02. Bahan uji komposit dibagi menjadi 3 fraksi volume, yaitu $20 \%, 30 \%$ dan $40 \%$. Hasil penelitian ini menunjukan bahwa densitas terendah berada pada komposit dengan fraksi volume $40 \%\left(\rho_{\min } 1,08 \mathrm{gr} / \mathrm{cm}^{3}\right)$, sedangkan densitas tertinggi terdapat pada fraksi volume 20 $\%$ serat $\left(\rho_{\text {maks }} 1,38 \mathrm{gr} / \mathrm{cm}^{3}\right)$. Untuk pengujian tarik, nilai kekuatan maksimum tertinggi berada pada komposit dengan fraksi volume $40 \%\left(\sigma_{\max } 32,27 \mathrm{~N} / \mathrm{mm}^{2}\right)$, sedangkan nilai kekuatan minimum berada pada posisi komposit dengan fraksi volume $20 \%\left(\sigma_{\min } 28,27 \mathrm{~N} / \mathrm{mm}^{2}\right)$.
\end{abstract}

Katakunci: serat, pelepah pisang,fraksi volume, kekuatan tarik

\begin{abstract}
An analysis on the influence on the variation of the volume fraction on the the density and the tensile strength of the Musa Paradisiaca fiber-epoxy. This study aims to analyze the influence of the volume fraction on the density and tensile strength composite substance of musa paradisiaca fiber-epoxy. One of the important factors in determining composite material characteristic is the volume faction of the matrix to the fiber. This study uses the Musa Paradisiaca Fiber, because of its abundance and eco-friendly. A tensile test with the specimen standard of ASTM 638-02 is employed in this study. The composite specimen is divided into 3 volume fractions, ie. $20 \%, 30 \%$, and $40 \%$. The result shows the minimum density obtained by the composite with the volume fraction of $40 \%$, $\left(\rho_{\min }\right.$ of $\left.1,08 \mathrm{gr} / \mathrm{cm}^{3}\right)$, while the maximum density is obtained by the composite with the volume fraction of $20 \%\left(\rho_{\max }\right.$ of $\left.1,38 \mathrm{gr} / \mathrm{cm}^{3}\right)$. In the tensile test, the maximum stress is obtained by the composite with the volume fraction of $20 \%\left(\sigma_{\min }\right.$ of $\left.32,27 \mathrm{~N} / \mathrm{mm}^{2}\right)$, while, the minimum is obtained by the composite with the volume fraction of $40 \%\left(\sigma_{\max }\right.$ of $\left.28,27 \mathrm{~N} / \mathrm{mm}^{2}\right)$.
\end{abstract}

Keywords: fiber, Musa Paradisiaca, volume fraction, tensile strength

\section{Pendahuluan}

Pisang telah dibudidayakan di Sulawesi Tenggara sejak lama. Selama ini tanaman pisang di budidayakan hanya untuk diambil buahnya sementara pelepah pisang hanya dibuang dan menjadi limbah dari tanaman pisang itu sendiri. Menyadari melimpahnya limbah pelepah pisang ini maka perlu adanya pemanfaatan pelepah pisang sehingga berguna dan menjadi komoditas yang mempunyai nilai ekonomis tinggi. Pelepah pisang jika diolah akan menjadi serat dengan kekuatan yang tinggi dan daya serapnya lebih bagus sehingga sangat baik jika digunakan sebagai bahan penguat pada komposit.

Ada berbagai alasan penting dalam pemanfaatan serat alami ini. Pemanfaatan ini tentunya diharapkan mendapatkan berbagai keuntungan, 
antara lain dari segi ramah lingkungan, segi kesehatan yang berkaitan dengan proses pembuatan komposit, segi kekuatan material (ditinjau dari kekuatan tarik dan kekuatan renggang), dan dari segi ketahanan terhadap korosi. Adapun produk komposit saat ini sering digunakan dalam berbagai kebutuhan. Dari segi kemaritiman, komposit sering digunakan untuk bodi kapal terutama kapal penjaga pantai, feri dan speed boat, peti kemas (peti ikan nelayan dan peti es) dan pipa fiber yang tahan terhadap karat (digunakan untuk mengalirkan fluida yang tidak berbahaya). Selain itu dari segi material, fiber sering dipergunakan pada perabot rumah, seperti atap fiber, dinding fiber dan berbagai kebutuhan dalam kehidupan lainnya (Schwartz MM. 1996).

Komposit serat merupakan material yang terdiri dari serat sebagai penguat dan matrik sebagai pengikatnya. Serat yang dimaksud dalam hal ini adalah serat alami yang berasal dari alam, tanpa melalui proses kimia dan industri. Pada umumnya serat alami yang dipakai berupa serat ijuk, serat bambu, serat rotan, serat pelepah pisang, serabut tandon kosong, serbuk papan, serabut kelapa, serat nenas, dan serat alami lainnya yang masih bisa dimanfaatkan (Jones, 1975 ).

Penelitian ini bertujuan menganalisis pengaruh fraksi volume terhadap densitas dan kekuatan tarik bahan komposit serat pelepah pisang-epoksi.

\section{Tinjauan Pustaka}

\section{Material Komposit dan Komponen Komposit}

Komposit merupakan bahan padatan yang dihasilkan dari dua gabungan atau lebih bahan yang berlainan untuk mendapatkan ciri-ciri yang lebih baik yang tidak dapat diperoleh dari setiap komponennya. Komposit yang dihasilkan bukan saja dapat memiliki sifat mekanik yang lebih baik baik tetapi juga sifat kimia, sifat panas dan berbagai sifat yang lain (Gibson,1994).

\section{Matriks}

Matriks adalah bahan yang diperkuat oleh serat penguat yang berfungsi mengikat serat yang satu dengan yang lainnya. Bahan yang paling umum dipakai sebagai matriks adalah metal atau polimer. Bahan plastik merupakan salah satu matriks resin epoksi. Bahan ini telah mengalami reaksi kimia oleh reaksi panas atau katalis. Plastik tidak dapat dicairkan kembali dan diproses kembali dan jika dipanasi pada suhu tinggi akan terurai dan rusak. Salah satu jenis plastik adalah plastik termoset. Plastik termoset ini salah satunya adalah epoksi. Keuntungan plastik termoset dalam aplikasi perencanaan teknik adalah kekakuan tinggi, kestabilan suhu tinggi, kestabilan dimensi tinggi, resistensi terhadap mulur dan deformasi di bawah pembebanan, ringan, dan sifat isolasi termal dan listrik yang tinggi (Gibson,1994).

\section{Serat}

Komponen penguat dari komposit adalah serat. Secara umum dapat dikatakan bahwa fungsi serat adalah sebagai penguat bahan untuk memperkuat komposit sehingga sifat-sifat mekaniknya lebih baik bila dibandingkan dengan tanpa serat penguat. Selain itu serat juga menghemat penggunaan resin. Beberapa syarat untuk dapat memperkuat matriks antara lain serat mempunyai modulus elastisitas yang tinggi dan mampu menerima perubahan gaya yang bekerja padanya. Arah serat mempengaruhi jumlah serat yang dapat diisikan kedalam matriks. Makin cermat penataannya, makin banyak penguat yang dapat dimasukkan. Arah serat penguat menentukan kekuatan komposit, sesuai dengan arah kekuatan maksimum (Schwartz,1994).

\section{Pisang Kepok (Musa Paradisiaca)}

Pisang adalah tanaman buah yang berasal dari kawasan di Asia Tenggara (termasuk Indonesia). Tanaman ini kemudian menyebar ke Afrika (Madagaskar) dan Amerika Selatan dan Tengah. Budidaya pisang sesuai dengan iklim di Indonesia baik dataran rendah maupun tinggi, akan mencapai optimal pada suhu $18-27^{\circ} \mathrm{C}$, dan secara teknis mudah dibudidayakan. Produksi pisang adalah produksi buah terbesar di Indonesia (40\% dari produksi buah nasional). Budidaya pisang hampir ada di seluruh wilayah di Indonesia (Diharjo dkk, 2000).

Keunggulan menggunakan serat alami (natural fiber) untuk menggantikan sebagian serat kaca pada komposit dengan penguat plastik, adalah dapat diperoleh penampilan yang lebih baik dan juga memperbaiki beberapa sifatnya (Diharjo dkk, 2000), yaitu :
a. Mengurangi berat
b. Dapat didaur ulang
c. Sebagai langkah untuk bumi hijau (green movement)
d. Mengurangi molding cycle 


\section{DINAMIKA Jurnal Ilmiah Teknik Mesin}

e. Biaya yang lebih kompetitif

f. Performance material yang lebih baik.

Pada material komposit, serat merupakan penguat yang memiliki kekuatan tarik dan kekakuan yang tinggi. Sementara itu, matriks berikatan bersama dengan serat mentransmisikan shear forces dan juga berfungsi sebagai coating. Sifat mekanik dari serat ditentukan oleh kekuatan tariknya dan kekakuannya. Kekuatan dari komposit yang dihasilkan sendiri ditentukan dari luas permukaan kontak antara matriks dan penguatnya. Serat yang lebih kecil akan memiliki luas permukaan kontak yang lebih besar sehingga sifat adhesi yang lebih baik. Kriteria pemilihan fiber-reinforced yang baik tergantung dari beberapa aspek, seperti (Schwartz,1984) :

a. Elongasi saat patah

b. Kestabilan thermal

c. Sifat tarik menarik (adhesi) antara serat dan matriks

d. Harga dan biaya produksinya.

\section{Penentuan Komposisi Volume Komposit}

Salah satu faktor yang sangat penting dalam menentukan karakteristik material komposit adalah kandungan (presentase) antara matriks dan serat. Sebelum melakukan proses pencetakan komposit, telebih dahulu dilakukan penghitungan mengenai volume komposit $\left(\mathrm{V}_{\mathrm{c}}\right)$, volume serat $\left(\mathrm{V}_{\mathrm{s}}\right)$ dan massa serat $\left(\mathrm{m}_{\mathrm{s}}\right)$ sebelum komposit dicetak (Gibson,1994).

Volume Komposit $\left(\mathrm{V}_{\mathrm{c}}\right)$ dapat dihitung dengan menggunakan persamaan:

$$
V c=\text { P.L.T }
$$

di mana:

$\mathrm{V}_{\mathrm{c}} \quad$ : Volume komposit sebelum dicetak $\left(\mathrm{m}^{3}\right)$

$\mathrm{P} \quad$ : Panjang komposit sebelum dicetak (m)

L : Lebar komposit sebelum dicetak (m)

$\mathrm{T} \quad$ : Tinggi komposit sebelum dicetak (m)

Volume serat $\left(\mathrm{V}_{\mathrm{s}}\right)$ dapat dihitung dengan menggunakan persamaan :

$$
V_{s}=\frac{f_{v s} x V_{c}}{100 \%}
$$

dimana:

$\mathrm{V}_{\mathrm{s}} \quad$ : Volume serat sebelum dicetak $\left(\mathrm{m}^{3}\right)$

$\mathrm{f}_{\mathrm{vs}} \quad$ : Fraksi volume serat yang digunakan (\%)
Massa serat $\left(\mathrm{m}_{\mathrm{s}}\right)$ dapat dihitung dengan menggunakan persamaan :

$$
m_{s}=\rho_{s} \cdot V_{s}
$$

di mana:

$\mathrm{m}_{\mathrm{s}} \quad$ :Massa serat sebelum dicetak (kg)

$\rho_{\mathrm{s}} \quad$ :Massa jenis serat sebelum dicetak $\left(\mathrm{kg} / \mathrm{m}^{3}\right)$

\section{Metodologi Penelitian}

\section{Tempat, Alat, dan Bahan Penelitian}

Penelitian ini dilakukan di Laboratorium Teknologi Mekanik, Fakultas Teknik Universitas Halu Oleo.

Peralatan yang digunakan dalam penelitian terdiri dari:

a. Mistar, untuk pengukuran dimensi dari spesimen.

b. Cetakan kaca, sebagai media pembuatan spesimen.

c. Gelas ukur, untuk mengukur volume resin dan serat.

d. Wadah, sebagai tempat pencampuran resin, serat dan hardener (katalis).

e. Timbangan digunakan untuk menimbang seberapa berat resin dan serat yang akan dicampur dalam proses pembuatan komposit sesuai dengan fraksi volume yang ditentukan.

f. Lem kaca (silicone glass)

g. Gunting, silet, penggaris, dan jangka sorong.

h. Amplas dan gurinda potong, untuk meratakan dan memotong spesimen sesuai ukuran standar.

Bahan yang digunakan :

a. Serat Pelepah pisang untuk penguat matriks.

b. Resin epoxy dan hardener untuk matriks.

c. Wax (mirror glaze) untuk memudahkan membuka cetakan.

\section{Prosedur Penelitian}

Pembuatan sampel dilakukan dengan mempersiapkan bahan penyusun komposit, berupa serat pelepah pisang, resin epoksi, dan hardener. Serat pelepah pisang disusun dengan arah lurus kemudian menyiapkan resin yang telah dicampur katalis. Spesimen dicetak dengan variasi fraksi volume $20 \%$, $30 \%$, dan $40 \%$ menggunakan cetakan kaca yang yang berbentuk sampel pengujian tarik standar ASTM D 638-02. 
Pengujian yang dilakukan terhadap komposit yaitu pengujian tarik. Bentuk bahan untuk uji tarik dengan dimensinya ditunjukkan pada gambar berikut berdasarkan American Society For Testing and Materials (ASTM) D 638 - 02.

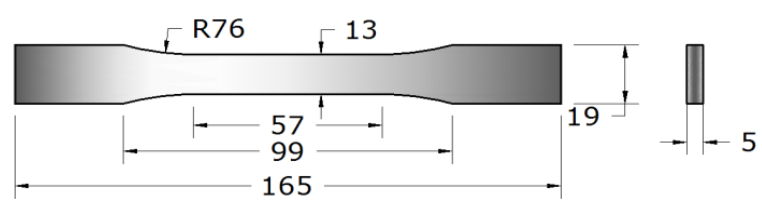

Gambar 1. Bentuk bahan dan dimensinya untuk uji tarik

\section{Hasil dan Pembahasan}

Kekuatan tarik komposit yang diperkuat serbuk pelepah pisang serat lurus dengan matriks epoxy resin diuji mengunakan mesin uji tarik Universal Testing Machine merek Shimadzutype AGS-X kapasitas $1000 \mathrm{~kg}$, yang dilengkapi alat penyimpan data hasil uji secara otomatis ke komputer.

\section{Densitas Komposit}

Tabel berikut adalah hasil perhitungan setiap fraksi volume komposit :

Tabel 1. Hasil pengujian densitas komposit serat pelepah pisang - matriks epoksi

\begin{tabular}{cccccc}
\hline $\begin{array}{c}\text { Fraksi } \\
\text { Volume } \\
\text { Serat }\end{array}$ & $\begin{array}{c}\text { Volume } \\
\text { Komposit } \\
\left(\mathbf{c m}^{3}\right)\end{array}$ & $\begin{array}{c}\text { Berat } \\
\text { Serat } \\
(\mathbf{g r})\end{array}$ & $\begin{array}{c}\text { Berat } \\
\text { Matriks } \\
(\mathbf{g r})\end{array}$ & $\begin{array}{c}\text { Berat } \\
\text { Komposit } \\
(\mathbf{g r})\end{array}$ & $\begin{array}{c}\text { Densitas } \\
\text { Komposit } \\
(\boldsymbol{\rho}) \\
\left(\mathbf{g r} / \mathbf{c m}^{3}\right)\end{array}$ \\
\hline $20 \%$ & 15,675 & 4,076 & 17,556 & 21,632 & 1,38 \\
\hline $30 \%$ & 15,675 & 6,113 & 15,361 & 21,475 & 1,37 \\
\hline $40 \%$ & 15,675 & 8,151 & 8,778 & 16,929 & 1,08 \\
\hline
\end{tabular}

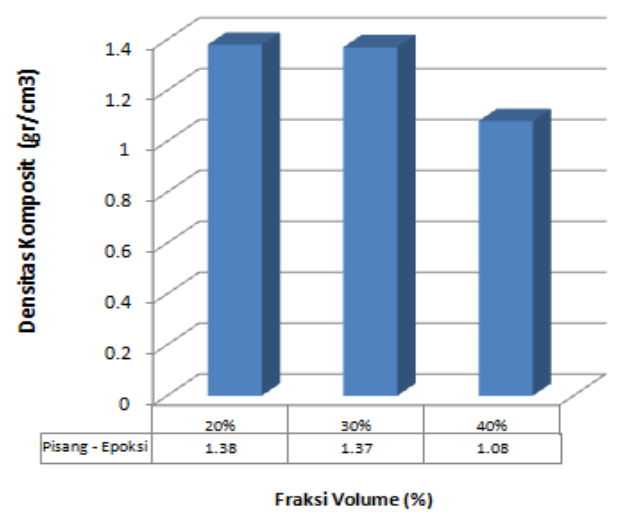

Gambar 2. Fraksi volume vs densitas komposit
Dari hasil perhitungan fraksi volume serat terlihat bahwa peningkatan fraksi serat akan menyebabkan berkurangnya berat total komposit ; berat terendah terdapat pada fraksi volume $40 \%(16,929$ gr $)$, sedangkan berat komposit yang tertinggi terdapat pada fraksi volume $20 \%$ serat $(21,632 \mathrm{gr})$.

Serat pelepah pisang digunakan sebagai pengisi di dalam matriks agar kekuatan komposit meningkat. Pada penelitian ini densitas komposit pada fraksi volume $20 \%, 30 \%$, dan $40 \%$ berturut-turut diperoleh $1,38 \mathrm{gr} / \mathrm{cm}^{3}, 1,37 \mathrm{gr} / \mathrm{cm}^{3}$, dan 1,08 $\mathrm{gr} / \mathrm{cm}^{3}$. Hal ini menunjukan bahwa penambahan fraksi volume hingga $40 \%$ dapat menyebabkan penurunan densitas komposit. Hal ini disebabkan karena densitas serat yang lebih rendah dari densitas resin epoksi.

\section{Kekuatan Tarik}

Hasil perhitungan kekuatan tarik selengkapnya dari masing-masing variasi fraksi volume dapat dilihat pada tabel 2 berikut :

Tabel 2. Hasil pengujian tarik komposit serat pelepah pisang - matriks epoksi

\begin{tabular}{lccc}
\hline Jenis Komposit & $\begin{array}{c}\text { Fraksi } \\
\text { Serat }\end{array}$ & $\begin{array}{c}\boldsymbol{\sigma}_{\text {maks }} \\
\left(\mathbf{N} / \mathbf{m m}^{2}\right)\end{array}$ & $\begin{array}{c}\square \text { maks } \\
\left(\mathbf{N} / \mathbf{m m}^{2}\right)\end{array}$ \\
\hline \multirow{2}{*}{ Pisang - Epoksi } & $20 \%$ & 2.923 & 2.051 \\
& $30 \%$ & 2.667 & 2.667 \\
& $40 \%$ & 2.051 & 2.923 \\
\hline
\end{tabular}

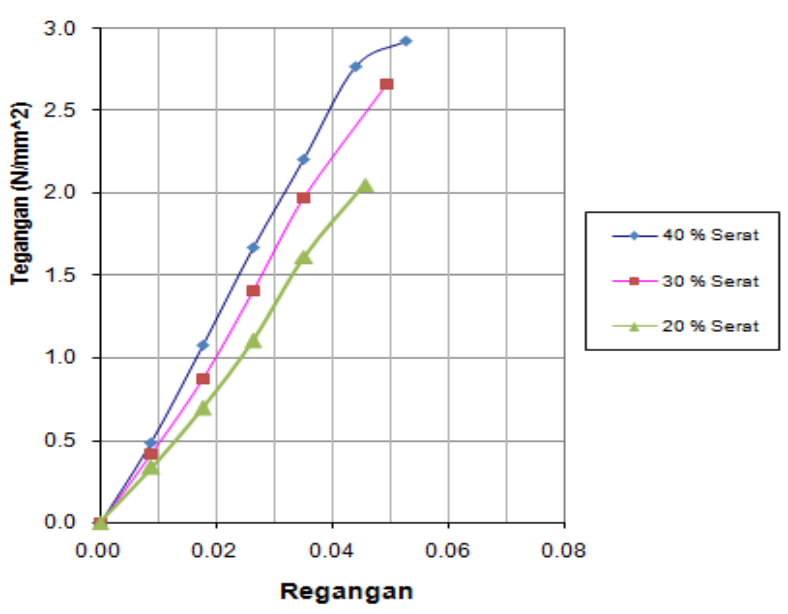

Gambar 3. Tegangan vs regangan 
Gambar 3 menunjukkan bahwa kekuatan tarik komposit serat pelepah pisang yang tertinggi adalah $2.923 \mathrm{~N} / \mathrm{mm}^{2}$ pada pada fraksi volume 40 $\%$. Nilai ini menurun pada fraksi volume $30 \%$ $\left(2,667 \mathrm{~N} / \mathrm{mm}^{2}\right)$ dan terendah pada arah fraksi volume $20 \%\left(2,051 \mathrm{~N} / \mathrm{mm}^{2}\right)$. Penurunan kekuatan tarik pada fraksi volume $30 \%$ dan $20 \%$ disebabkan karena kurangnya serat yang mendistribusikan gaya tarik secara penuh. Penambahan fraksi volume serat sampai dengan batas tertentu dapat mempengaruhi kekuatan serat pelepah pisang sebagai penguat komposit.

\section{Kesimpulan}

Kesimpulan yang diperoleh dari penelitian adalah peningkatan fraksi volume serat akan menyebabkan berkurangnya berat total komposit sehingga menurunkan nilai densitas komposit. Nilai terendah dari densitas komposit terdapat pada fraksi volume $40 \%\left(1,08 \mathrm{gr} / \mathrm{cm}^{3}\right)$, sedangkan densitas komposit terbesar terdapat pada fraksi volume $20 \%$ serat $\left(1,38 \mathrm{gr} / \mathrm{cm}^{3}\right)$. Selain itu, penambahan serat pelepah pisang pada komposit dengan fraksi volume $20 \%, 30 \%$ dan $40 \%$, dapat mempengaruhi nilai kekuatan tarik. Kekuatan tarik maksimum sebesar $2.923 \mathrm{~N} / \mathrm{mm}^{2}$ pada fraksi volume $40 \%$,sedangkan untuk kekuatan tarik terendah $2.051 \mathrm{~N} / \mathrm{mm}^{2}$ terdapat pada fraksi volume $20 \%$.

\section{Daftar Pustaka}

Diharjo K, Triyono T. 2000, "Material Teknik, Buku Pegangan Kuliah”. UNS Press, Surakarta.

Gibson RF. 1994, "Principles Processing and Composite Material". Mc-Granhill Book Company, New York.

Jones RM. 1975, "Mechanics of Composite Materials". Scripta Book, Company Washington DC.

Schwartz MM. 1984. "Composite Material, Handbook”. McGraw Hill, Inc., New York, USA.

Schwartz MM. 1996, “Composite Meterials Polimers, Ceramics and Metal Matrices".Prentice-Hall, USA. 
DINAMIKA Jurnal Ilmiah Teknik Mesin 